\title{
MODELING THE PROCESS OF BUSINESS MANAGEMENT SYSTEMS CONTROL
}

Innovative trends in production management increasingly involve implementation and auditing of standardized management systems according to ISO standards. Within the paper are presented the results of research focused on optimization of auditing system processes in the area of quality, environment and safety. There was constructed an algorithm and quantified mathematical model of integrated auditing and using Gantt chart, the visualization of annual auditing plan was realized. Verified and validated proposed model offers possibilities of its extending for the capacity management and indicators of integrated auditing processes of business management systems.

Keywords: Modeling, control, management systems, auditing.

\section{Introduction}

In the current business practice, with an increasing number of standards for the management systems implementation in organizations, increase also demands on their resources and controlling. Organizations are overloaded by 'continuous' auditing of their performance. Optimization of the traditional approach to audit results in the creation of methodical process of control via integrated auditing [1 and 2].

The aim of our research is to design a methodical process for optimizing the traditional auditing through integration of individual audit processes based on the requirements of ISO standards for partial aspects of management. When optimizing the traditional auditing methodologies, the methods of operational and systems analysis were used.

Research was based on the findings of the monitoring the situation of traditional (separately performed) and integrated business management systems auditing at home and abroad, as well as information gained from consultations with leading theorists and practitioners, in particular:

- lack of methodologies for optimizing management control procedures through an integrated auditing of implemented management systems in the organization,

- absence of application of management approaches in the process of integrated management systems auditing,

- undervaluation of advantages and benefits resulting from the integrated auditing in the audit practice.

\section{Optimalization the processes of business management systems auditing}

Starting from the formulation of issues and goals of research, detailed analysis of auditing process and possible scenarios of its development was carried out. Results of analysis served for designing the dynamic model with direct impact of input values of the model. For model designing, the methods of operational and systemic analysis were applied [3].

In the introductory phase of the model designing, the following issues have to be solved:

- analysis of the current knowledge-base,

- obtaining input data from the partial conclusions of the analysis,

- definition of the research object in measurable units,

- finding a method of mathematical description of the problem according to ISO standards,

- constructing a flowchart of auditing for the needs of model creation, determining its topology, the positions of entities and sessions between them,

- search for output data in such units that enables the comparison of output data (traditional - separated and integrated auditing).

Based on the detailed analysis of the problems and gained experiences, the model was designed and possibilities of its application in optimization of control by auditing in auditing practice were proposed.

\footnotetext{
* ${ }^{1}$ Milan Majernik, ${ }^{\text {Naquib Daneshjo, }{ }^{2} \text { Katarina Repkova Stofkova }}$

${ }^{1}$ Department of Management, Faculty of Business Economics with seat in Kosice, University of Economics in Bratislava, Kosice, Slovakia

${ }^{2}$ Faculty of Operation and Economics of Transport and Communications, University of Zilina, Slovakia

E-mail: milan.majernik@euke.sk
} 
At the beginning of creating flowchart of control audit, the audit processes and their topology were identified. Topology of the process of audit subsequently formed the input to the creation of the model.

Altogether there were identified at least 12 audit processes (Fig. 1). Determined processes are universal, applicable to all types (process, system) and forms (internal, external, certification, etc.) audits. If necessary, they can be extended to a range of other processes [4].

When developing the model, following parameters were determined:

a) Type, or form of audit - we considered the system audits of four management systems: quality management (audit 1), environmental audit (audit 2), occupational health and safety (audit 3) and information security audit (audit 4).

b) Term of audit realization (specific week of the year) important for the model because of obligation to create the annual audit plan and because of its comprehensive approach to management.

c) Examined organizational unit of the organization - the necessary requirements for audit realization.

d) The presence of unconformities during the audit - affects the duration of the post-audit actions i.e. embedding mandatory corrective and preventive measures [3].

Generation of random numbers (Table 1) was carried out with pre-defined intervals of parameters and constants of aggregate of integers and the aggregates of logic statements [true - false]. The basis for created generator was the use of the cyclic intervals, where for each cyclic interval was performed variety of orders, or complex orders. Indexing variables were subsequently used for determining values of the above mentioned aggregates, and were via specific commands continuously stored in a text file after each cycle of the program. The number of cycles was defined by the sponsor on the basis of predetermined requirements resulting from the various ISO standards relevant for particular management systems (QMS, EMS, HSMS, ISMS) and the requirements of the model.

For the purpose of constructing a generator we used programming language Turbo Pascal 6.0, and we followed these steps:

- problem analysis,

- defining declaration section,

- defining the executive (command) section.

For the first step it was necessary to analyze the detailed topology of audit process and determine variables, constants and cycles necessary for converting the input to the searched result. When defining the declaratory part, we identified categories of variables necessary for the program performance which we monitored during verification of the designed algorithm. In the last step, we transformed the algorithm into form of commands

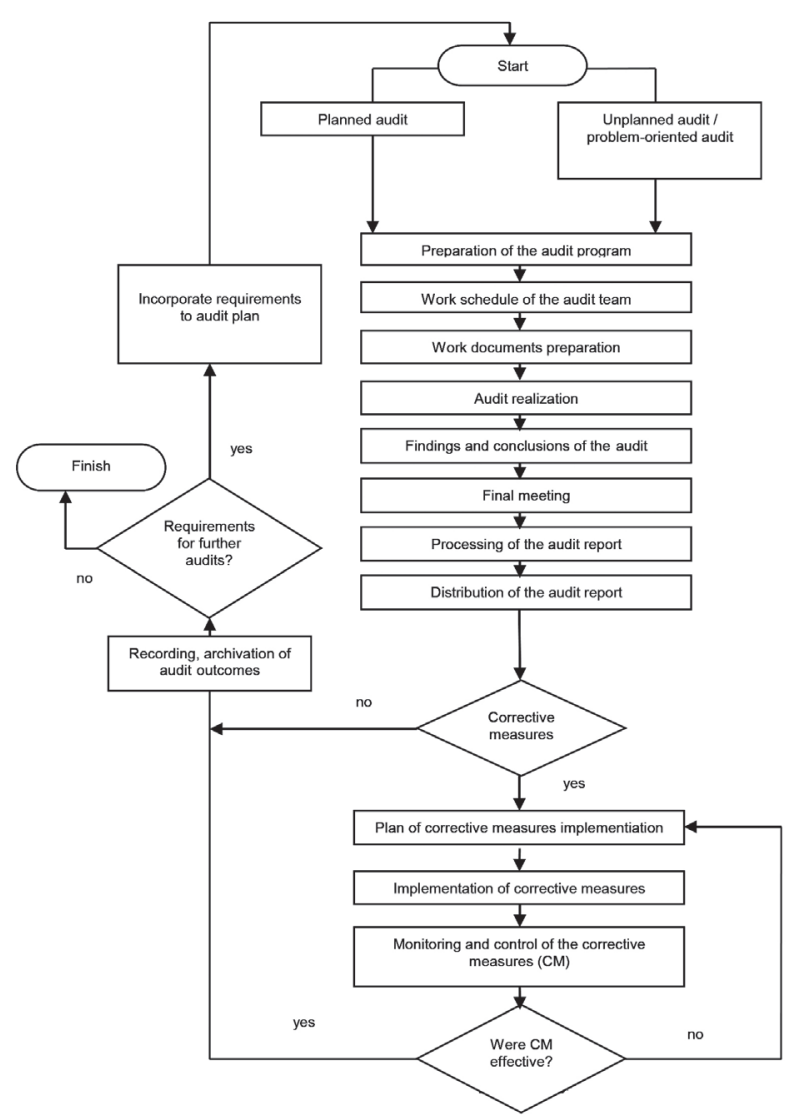

Fig. 1 General algorithm of the process of control audit

based on the structure of the programming language so that the commands comply input conditions of earlier carried out analysis of the problem.

\subsection{Formalization and quantification of mathematical model}

Based on requirements of ISO standards for key elements of the particular management system, we proposed a model of integrated auditing, which was created as a combination of the identified key processes of traditional auditing where optimization of the auditing process presents added value. We also focused on time saving of each audit process, which has a direct impact on reducing personnel and overhead costs, or otherwise it disproportionately increases the demand for capacity in relation to the performing of the mandatory annual audit plan of the organization.

The model is composed of two parts (Fig. 2):

- traditional approach to a separated auditing of management systems, sub-aspects

- integrated approach to auditing of management systems addressed in the first part of the model. 
Generated parameters for traditional auditing and quantified input values of the model

Table 1

\begin{tabular}{|c|c|c|c|c|c|c|c|}
\hline $\begin{array}{l}\text { Type or form of } \\
\text { audit (Vi) }\end{array}$ & $\begin{array}{c}\text { Audited } \\
\text { organizational unit } \\
\text { (Xi) }\end{array}$ & $\begin{array}{c}\text { Scheduling of } \\
\text { audit (week) (Yi) }\end{array}$ & $\begin{array}{c}\text { The occurrence of non- } \\
\text { conformities during the } \\
\text { audit (Zi) }\end{array}$ & $\begin{array}{l}\text { Total duration of } \\
\text { audit } \\
\text { (days) }\end{array}$ & $\begin{array}{c}\text { Total } \\
\text { duration } \\
\text { of audit } \\
\text { (week) }\end{array}$ & $\begin{array}{l}\text { Start of audit } \\
\text { (week) }\end{array}$ & $\begin{array}{c}\text { End of audit } \\
\text { (week) }\end{array}$ \\
\hline 3 & 8 & 3 & 0 & 28 & 4 & 1 & 4 \\
\hline 4 & 1 & 3 & 1 & 28 & 4 & 2 & 5 \\
\hline 2 & 8 & 4 & 1 & 49 & 7 & 1 & 7 \\
\hline 4 & 6 & 4 & 0 & 21 & 3 & 3 & 5 \\
\hline 4 & 10 & 4 & 0 & 21 & 3 & 3 & 5 \\
\hline 2 & 9 & 5 & 1 & 49 & 7 & 2 & 8 \\
\hline 3 & 9 & 5 & 0 & 28 & 4 & 3 & 6 \\
\hline 2 & 6 & 6 & 0 & 42 & 6 & 3 & 8 \\
\hline 2 & 10 & 8 & 1 & 49 & 7 & 5 & 11 \\
\hline 3 & 2 & 9 & 1 & 35 & 5 & 7 & 11 \\
\hline 1 & 3 & 10 & 0 & 49 & 7 & 6 & 12 \\
\hline 1 & 6 & 12 & 1 & 63 & 9 & 8 & 16 \\
\hline 1 & 10 & 12 & 1 & 63 & 9 & 8 & 16 \\
\hline 3 & 7 & 13 & 1 & 35 & 5 & 11 & 15 \\
\hline 2 & 1 & 18 & 1 & 49 & 7 & 15 & 21 \\
\hline 1 & 1 & 19 & 0 & 49 & 7 & 15 & 21 \\
\hline 1 & 7 & 20 & 0 & 49 & 7 & 16 & 22 \\
\hline 4 & 9 & 21 & 0 & 21 & 3 & 20 & 22 \\
\hline 1 & 2 & 23 & 1 & 63 & 9 & 19 & 27 \\
\hline 2 & 3 & 24 & 0 & 42 & 6 & 21 & 26 \\
\hline 2 & 2 & 26 & 0 & 42 & 6 & 23 & 28 \\
\hline 4 & 4 & 27 & 0 & 21 & 3 & 26 & 28 \\
\hline 3 & 10 & 28 & 0 & 28 & 4 & 26 & 29 \\
\hline 4 & 7 & 28 & 0 & 21 & 3 & 27 & 29 \\
\hline 4 & 8 & 28 & 0 & 21 & 3 & 27 & 29 \\
\hline 2 & 4 & 30 & 0 & 42 & 6 & 27 & 32 \\
\hline 2 & 7 & 32 & 1 & 49 & 7 & 29 & 35 \\
\hline 3 & 1 & 32 & 0 & 28 & 4 & 30 & 33 \\
\hline 3 & 6 & 32 & 0 & 28 & 4 & 30 & 33 \\
\hline 1 & 9 & 34 & 0 & 49 & 7 & 30 & 36 \\
\hline 1 & 5 & 38 & 0 & 49 & 7 & 34 & 40 \\
\hline 1 & 4 & 39 & 1 & 63 & 9 & 35 & 43 \\
\hline 2 & 5 & 39 & 0 & 42 & 6 & 36 & 41 \\
\hline 4 & 2 & 39 & 1 & 28 & 4 & 38 & 41 \\
\hline 1 & 8 & 41 & 1 & 63 & 9 & 37 & 45 \\
\hline 3 & 3 & 43 & 0 & 28 & 4 & 41 & 44 \\
\hline 3 & 5 & 46 & 0 & 28 & 4 & 44 & 47 \\
\hline 4 & 3 & 46 & 1 & 28 & 4 & 45 & 48 \\
\hline 4 & 5 & 46 & 0 & 21 & 3 & 45 & 47 \\
\hline 3 & 4 & 49 & 1 & 35 & 5 & 47 & 51 \\
\hline
\end{tabular}


Both parts of the model are placed abreast, so the output drawn from different parts of the model are mutually comparable.

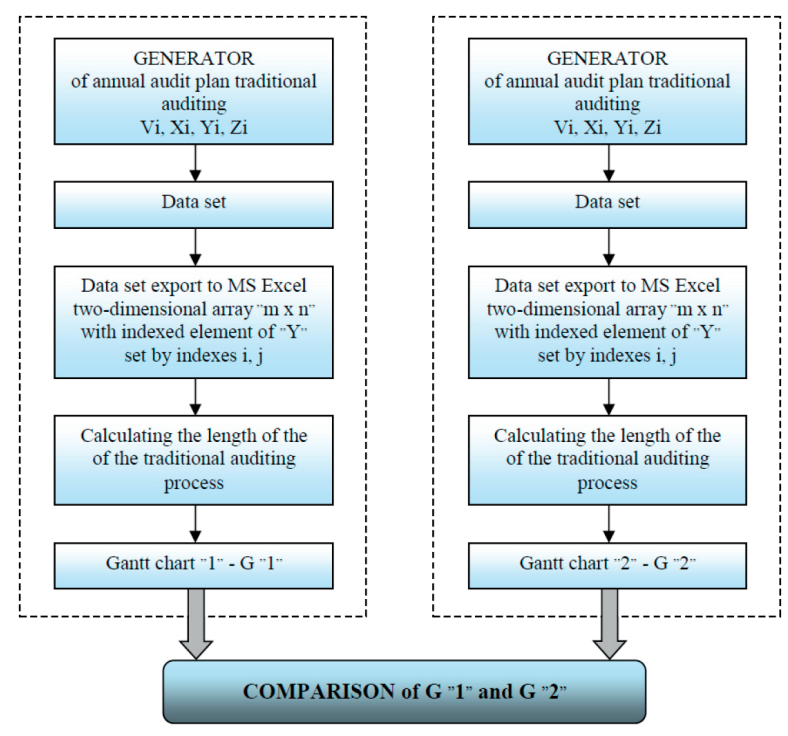

Fig. 2 Mathematical model of auditing

The basis of integrated auditing is that it is focused on auditing of individual management systems comprehensively; it is focused to the relevant auditing management systems as a whole, jointly, not separately. Model formation we realized with the support of Microsoft Office Excel, 2007.

In phase of quantification, the model was filled with concrete credible and objective data. The reliability of the data was achieved by expert estimates of their values and objectivity of data generation was achieved by using the program for generation of random numbers. Figure 2 characterizes the record and logics of model created.

Table 2 shows the total duration of formalized processes of individual audits. From the time evaluation of these processes (traditional auditing), we consequently quantified mean value, made correction of mean value for the purposes of the model, we also set a maximum and total sum of the duration of individual processes.

The model of quantified data for traditional auditing and integrated auditing expressing the relationship between these data provides several solutions, outcomes and conclusions. The first is creation of a Gantt chart of annual audit plan for traditional auditing as well as integrated auditing.

Using the Gantt chart we gained visualization of annual audit plan for both approaches to audit. The duration of each audit is shown on the horizontal axis and the vertical axis shows all planned audits, which - based on ISO standards - have to be performed during the year. The duration of the audit is shown on rectangle whose left side presents the point of the audit start and the right side presents the point of the planned end of the audit. The duration of each audit includes time assessment of the length of all 12 identified and formalized audit processes. In traditional auditing it is necessary to carry out 40 audits per year while in the case of an integrated approach to audit there should be carried out only 10 audits per year. Visualization of the annual audit plan we realized with the support of Microsoft Excel using conditional formatting functions

Visualization of the annual audit plan for traditional auditing, showed in Fig. 3, reflects the current situation, quite common today, in the field of control via auditing of management systems. In principle, it is characterized by the fact that organizations are overloaded by continuous auditing of management systems, which have to be implemented in accordance with globally recognized standards.

Visualization of the annual audit plan within an integrated approach to auditing (Fig. 4) shows significantly reduced time requirements obtained with the newly designed methodology for establishing an annual integrated audit plan compared with the traditional approach to auditing.

Time consumption of audits and individual processes in weeks

Table 2

\begin{tabular}{|c|c|c|c|c|c|c|c|c|c|c|c|c|}
\hline $\begin{array}{l}\text { Process } \\
\text { Audit }\end{array}$ & 1 & 2 & 3 & 4 & 5 & 6 & 7 & 8 & 9 & 10 & 11 & 12 \\
\hline Audit 1 & 10 & 3 & 15 & 7 & 2 & 1 & 2 & 7 & 2 & 7 & 5 & 2 \\
\hline Audit 2 & 6 & 2 & 13 & 7 & 2 & 1 & 1 & 7 & 2 & 3 & 3 & 2 \\
\hline Audit 3 & 5 & 2 & 7 & 7 & 1 & 1 & 2 & 3 & 1 & 3 & 2 & 1 \\
\hline Audit 4 & 2 & 1 & 4 & 7 & 2 & 1 & 1 & 2 & 1 & 4 & 2 & 1 \\
\hline Mean & 5.75 & 2.00 & 9.75 & 7.00 & 1.75 & 1.00 & 1.50 & 4.75 & 1.50 & 4.25 & 3.00 & 1.50 \\
\hline $\begin{array}{l}\text { Correction of mean value for the } \\
\text { purposes of the model }\end{array}$ & 6 & 2 & 10 & 7 & 2 & 1 & 2 & 5 & 2 & 5 & 3 & 2 \\
\hline Maximum & 10 & 3 & 15 & 7 & 2 & 1 & 2 & 7 & 2 & 7 & 5 & 2 \\
\hline Total & 23 & 8 & 39 & 28 & 7 & 4 & 6 & 19 & 6 & 17 & 12 & 6 \\
\hline
\end{tabular}




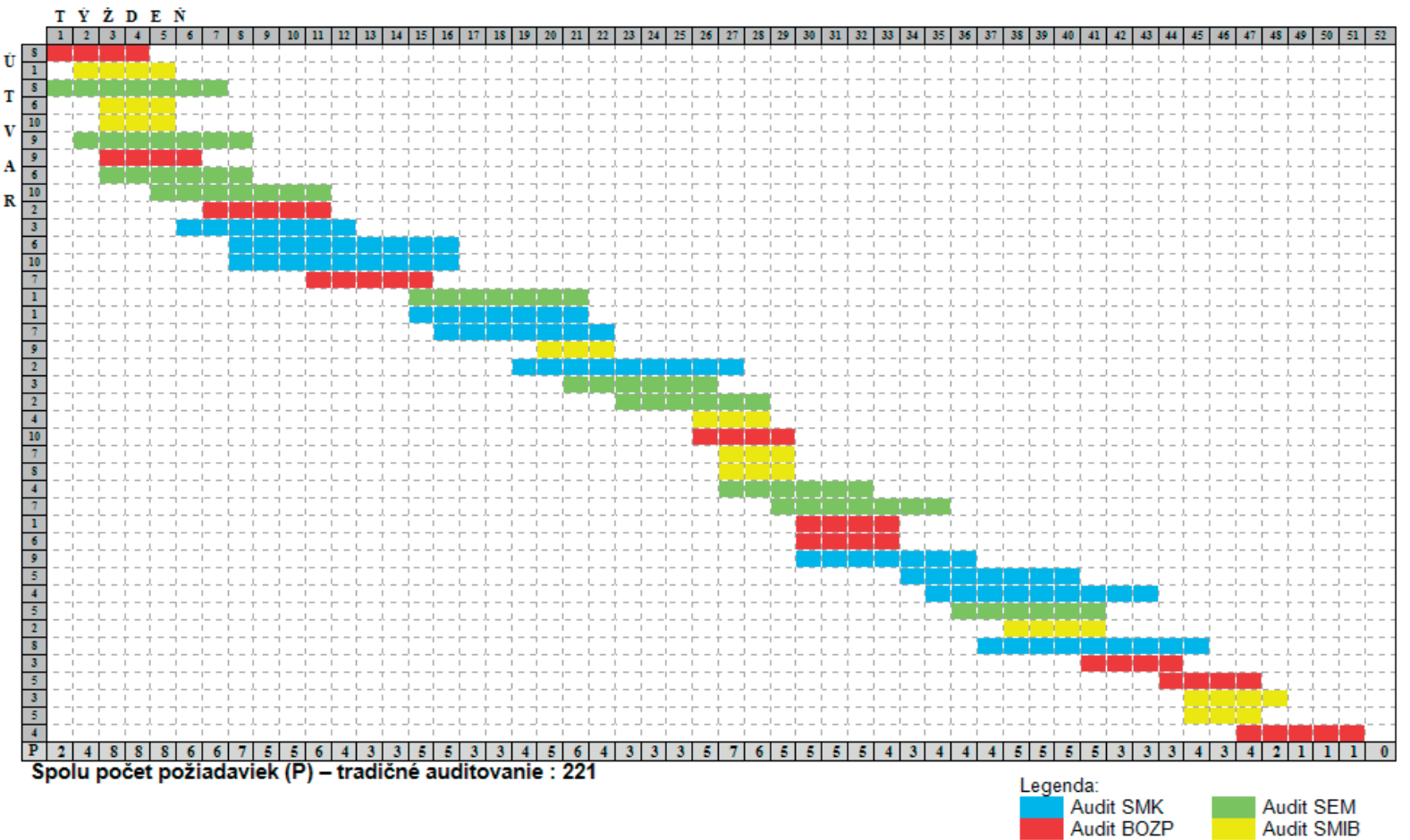

Fig. 3 Visualization of the annual audit plan, traditional auditing (G "1")

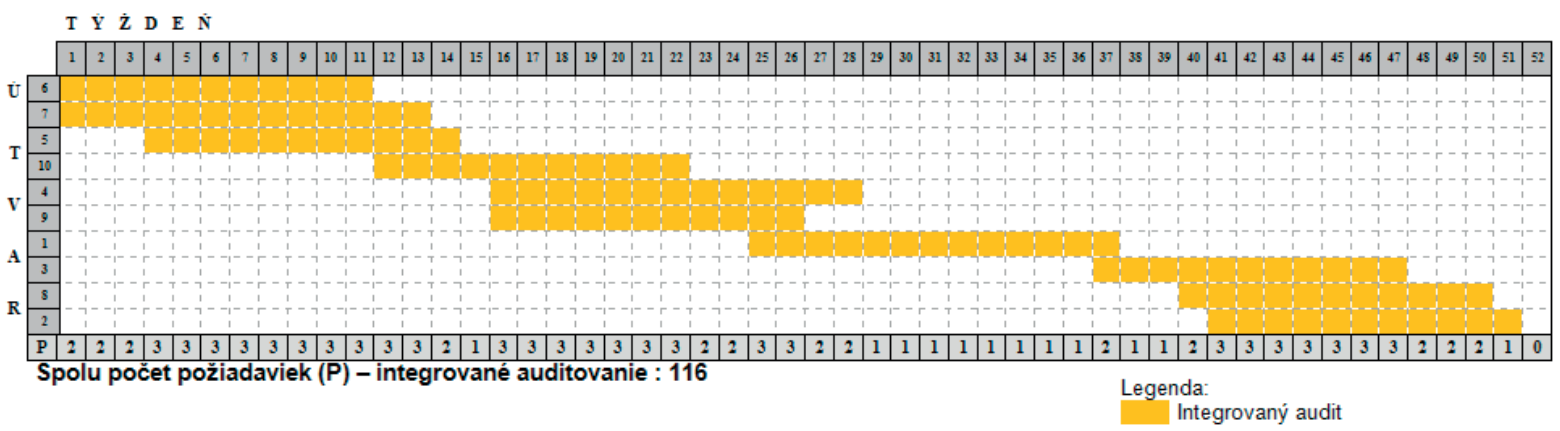

Fig. 4 Visualization of the annual audit plan, - integrated auditing (G "2")

\section{Conclusion}

Outgoing of analysis of traditional and integrated auditing and comparison of outcomes, we came to significant conclusions:

- by visualization of the annual audit plans we can determine which week and to what extent are audit teams work-loaded;

- traditional auditing is more capacity demanding (resources, funds, time), as shown by the total number of requirements that need to be met during the year in traditional auditing (221-conformities), whilst integrated auditing reduces total number of requirements to 116 .

Based on the annual audit plan, in the traditional approach to audit there have to be carried out 40 audits per year. When quantified capability of one audit team is 5 audits per year, we will need 8 audit teams to perform all necessary audits set in annual audit plan. In case of integrated auditing, only 3 audit teams are required to meet annual audit plan. The main results of research are summarized in Table 3.

Optimization process of standardized business management systems control through audit is carried out by modeling of the integrated auditing using operational and system analysis. Management approach of issue analysis using method "per partes" can provide the required input data. Therefore, based on the methodology, data were used for searching the optima in the studied areas.

Formalization of the model and using methods of operational and system analysis, optimization steps have been proposed, 
Main results of research

Table 3

\begin{tabular}{|c|c|c|}
\hline \multirow{2}{*}{ The main areas of achievements } & \multicolumn{2}{|l|}{ RESULTS } \\
\hline & Traditional approach to auditing & Integrated approach to auditing \\
\hline The total number of audit requirements during the year & 221 requirements & 116 requirements \\
\hline The workload of audit teams & inefficiently adjusted working time & efficiently adjusted working time \\
\hline Capacity demands & higher & lower \\
\hline Working ability of one audit team & 5 traditional audits per year & 4 integrated audits per year \\
\hline $\begin{array}{l}\text { The number of audit teams necessary to implement the } \\
\text { overall annual audit plan }\end{array}$ & 8 audit teams & 3 audit teams \\
\hline \multirow[t]{2}{*}{$\begin{array}{l}\text { The comparison results of the processes duration in } \\
\text { the planning stage of the audit in relation to the total } \\
\text { length of the individual audits - a demonstration of the } \\
\text { importance of the planning phase of the audit }\end{array}$} & $\begin{array}{l}\text { Traditional audit without corrective } \\
\text { measures: } \\
33 \%-57 \% \\
\text { (in relation to the total length of all } \\
\text { processes of a particular audit) }\end{array}$ & $\begin{array}{l}\text { Integrated audit without corrective } \\
\text { measures: } \\
67.53 \% \\
\text { of the total duration of the audit } \\
\text { processes }\end{array}$ \\
\hline & $\begin{array}{l}\text { Traditional audit with corrective measures: } \\
25 \%-44 \% \\
\text { (in relation to the total length of all } \\
\text { processes of a particular audit) }\end{array}$ & $\begin{array}{l}\text { Integrated audit with corrective measures: } \\
57.14 \% \\
\text { of the total duration of the audit } \\
\text { processes }\end{array}$ \\
\hline
\end{tabular}

which can serve as a tool in the application of queuing systems. By analyzing the various key elements of the model and their subsequent combination and integration, we have achieved a synergistic effect on the process of integrated management systems auditing for control purposes in Deming PDCA cycle of continuous improvement.

\section{Acknowledgement}

This work has been supported by the Scientific Grant Agency of the Ministry of Education of the Slovak Republic (Project VEGA 1/0733/15).

\section{References}

[1] BERNARDO, M., CASADESUS, M., KARAPETROVIC, S., HERAS, I.: An Empirical Study on the Integration of Management System Audit, J. of Cleaner Production, 18, 742-750, 2009, ISSN 0959-6526.

[2] CHOVANCOVA, J., BEDNAROVÁ, L., LIBERKO, I.: Environmental, Quality and Safety Management Systems Implementation with Focus on their Integration, ICEEE-2013, $4^{\text {th }}$ Intern. conference To protect our global environment of future generation, Budapest: Obuda University, 2013, 41-47, ISBN 978-615-5018-93-0.

[3] HOLlA, K., SimONOSOVA, M., CANDRAS, J., MALZ, S., COLlinS, A.: Results and Conclusions of the project Complex Model of Risk Assessment and Treatment on Industrial Processes (MOPORI), Communications - Scientific Letters of the University of Zilina, No. 1, 2015, 46-51, ISSN 1335-4205.

[4] MAJERNIK, M., SZARYSZOVA, P., HAKUlINOVA, A., MARKOVIC, J.: Accreditation, Certification, Auditing, University of Economics in Bratislava, Kosice, 2013, 204 p., ISBN 978-90-971555-0-6. 